\title{
EXPERIMENTAL DYNAMIC ANALYSIS ON A T100 MICROTURBINE CONNECTED WITH DIFFERENT VOLUME SIZES
}

\author{
Mario L. Ferrari* \\ mario.ferrari@unige.it \\ \begin{tabular}{c}
$\begin{array}{c}\text { Matteo Pascenti* } \\
\text { matteo.pascenti@unige.it }\end{array}$ \\
\hline
\end{tabular}
}

\author{
Federico Reggio** \\ federico.reggio@outlook.it
}

\author{
Paolo Silvestri** \\ p.silvestri@unige.it
}

\footnotetext{
*University of Genoa, DIME, Thermochemical Power group (TPG), Genova, Italy

**University of Genoa, DIME, Genova, Italy
}

\section{Aristide F. Massardo* massardo@unige.it}

\begin{abstract}
This paper shows experimental results obtained from a T100 microturbine connected with different volume sizes. The activity was carried out with the test rig developed at the University of Genoa for hybrid system emulation. However, these results apply to all the advanced cycles where a microturbine is connected with an additional external component responsible for volume size increase. Even if the tests were performed with a microturbine (for laboratory scale and for the related research interest in innovative cycles), similar analyses can be extended to on large size turbines. The main power systems including the effect of an additional volume connected with a turbine are: fuel cell based hybrid plants, humid cycles, externally fired layouts and innovative systems including high temperature thermal storage devices. Since in this case a $100 \mathrm{~kW}$ turbine was used, the volume was located between the recuperator outlet and the combustor inlet as in the typical cases related to small size plants. A modular vessel was used to perform and to compare the tests with different volume sizes.

To highlight the volume size effect, preliminary experimental results were carried out considering the transient response due to an on/off bleed valve operation. So, the main differences between system parameters obtained for a bleed line closing operation are compared considering three different volume sizes.

The main results reported in this paper are related to surge operations. This analysis was carried out to extend the knowledge about this risk condition: the systems equipped with large volume size connected with the machine present critical issues related to surge prevention especially during transient
\end{abstract}

operations. For instance, if the T100 machine is operating with large volume components, the standard shutdown procedure can produce surge condition. This behavior is due to a slow depressurization rate in comparison with a standard microturbine. So, to produce surge conditions in this test rig, a valve operating in the main air path was closed to generate unstable behavior. It was possible to compare the effect of different volume sizes on main properties of the system using a modular vessel. Particular focus was devoted to the operational curve plotted on the compressor map. The system was equipped with different dynamic probes to measure the vibrations during normal and surge operations. The frequency analysis showed significant vibration increase not only during surge events but also close to the unstable condition. In details, possible surge precursor indicators were obtained to be used for the detection of risky machine operations. Since these surge precursors are considered important parameters for the control system point of view, an extensive experimental analysis was carried out considering the influence of volume size. These precursors were defined to produce control data (e.g. an on/off signal for a bleed valve) for surge prevention. The experimental data collected during these tests are analyzed with the objective of designing control systems to prevent surge conditions.

\section{INTRODUCTION}

The development of advanced cycles based on gas turbine technology showed interesting performance improvement in terms of both efficiency and emission aspects [1-3]. While humid cycles and hybrid systems are designed for efficiency improvement (with related benefits on the $\mathrm{CO}_{2}$ emission reduction $[4,5]$ ), innovative plant layouts are devoted to the 
integration of renewable energy sources (e.g. a biomass combustion system or a solar concentration device [6-8]). The recent development of high temperature energy storage systems could drive gas turbine cycles toward further layout modifications $[9,10]$. In all the mentioned cases, the gas turbine connection with such additional components generates a size increase for the volume located between the compressor outlet and the combustor inlet [11-13].

The volume size increase is not significantly modifying the steady-state performance. In details, few changes in the properties are: additional pressure decay through the additional component and temperature decrease due to the large external surface of this mentioned additional device. However, important different effects are present during transient operations due to the increase in response modification. For this reason, the gas turbine control system has to be carefully modified considering the additional volume effect [14]. This is an important factor to ensure the safe operation of these advanced cycle power plants without creating any excessive stress on the components (such as temperature peaks in critical heat exchangers) or surge condition $[13,14]$. Such critical operations in a standard gas turbine with a large volume additional component are significantly important. This behavior is particularly significant in the systems which are affected by several additional constraints (such as fuel cell based hybrid systems [15-17]). This issue forces to develop a new turbine control system that has to satisfy a large number of additional constraints (such as temperature and pressure gradient limitations in fuel cells) with significant risks of incurring in surge operations [18,19]. For instance, if the turbines are operated in connection with large volume components, the standard shutdown procedure could be affected by a significant slow depressurization rate (in comparison with a standard layout) leading to surge conditions [20].

Although several authors have proposed control system solutions to compensate the volume increase effects [13,21-23], surge risk could be not completely avoided in case of unexpected conditions due to component degradation or partial failures [23]. Development of further surge prevention techniques based on measurable precursors are essential for the wide commercial diffusion of such innovative systems based on gas turbine technology. Since the compressor performance maps are not always available, reliable and representative of some operations (e.g. they are not able to take into account component degradation effects), hence surge prevention measures based on such maps are not able to safely prevent surge risks [20]. So, several authors presented activities to identify possible surge precursors [24,25]. For this reason, different precursors of surge event based on high frequency measurements (accelerometers) are proposed in this work. The detection of an operating condition too close to the surge zone is an essential information for the control system that can operate (e.g. opening a bleed valve) to remove the risk conditions.
Although this is a general issue to be considered for all these innovative gas turbine systems, in this paper attention is focused on small size plants like the T100 microturbine. This choice is due to the interest on innovative gas turbine systems for distributed generation (with a special attention on fuel cell hybrid systems) and to the availability of an experimental test rig based on a T100 turbine [14,20,26,27]. The experimental facility developed by the Thermochemical Power Group (TPG) at the University of Genoa was used in this work. It was necessary to perform tests on hybrid systems based on Solid Oxide Fuel Cell (SOFC) technology for analyzing the additional volume effects on gas turbines. Since previous works have demonstrated the importance of experimental results obtained with emulator plants [14,20,27,28], these experimental tests were conducted using a modular vessel (to change volume size) connected between the recuperator outlet duct and the combustor inlet, instead of including the actual additional components in the rig.

In this work the experimental analysis on the volume size effect was started considering preliminary experimental tests. They are related to the transient response obtained with a bleed valve closing. They are representative of bleed operations on such innovative systems, showing additional surge risk aspects related to the large volume transient response. Then, surge operations, produced by fractional opening decrease on the valves located in the main air path, were carried out. A comparison of results obtained with different volume sizes was performed focusing special attention on the operational curve related to the compressor map. A frequency analysis (measurements obtained with additional dynamic probes) was carried out to highlight the possible surge precursors to be included in an innovative control system which is able to prevent surge risks. Although some previous works [24,29] presented possible surge precursors, an important novel aspect of this paper regards properties to be collected by standard probes for control system operations. Attention is not simply focused on the machine, but the results presented here will also be essential for advanced turbine based cycles including a large volume additional component. Since commercial turbines are not equipped with surge detection systems (their standard operations are correctly managed by their commercial control systems), these results will be essential for plants including additional components. In such innovative plants (e.g. fuel cell based hybrid systems, humid cycles, externally fired layouts and plants including high temperature thermal storage devices) surge risk cannot be managed by standard control solutions especially during transient operations [14,15,22].

\section{NOMENCLATURE}

\section{Acronyms}

\begin{tabular}{ll}
\hline E. grid & Electrical grid \\
Ex & heat Exchanger \\
FFT & Fast Fourier Transform \\
M & Motor \\
REC & Recuperator
\end{tabular}




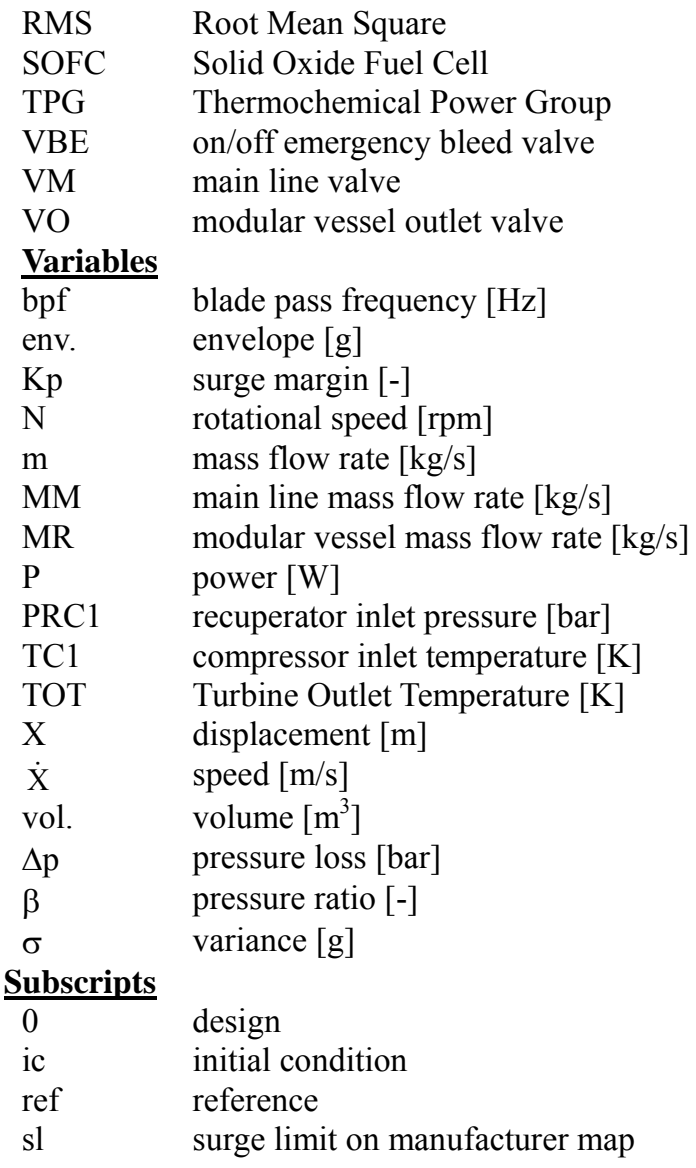

\section{TEST RIG}

The experimental test rig used in this work is based on a modified commercial recuperated microturbine (Turbec T100) connected with external vessels [14] (located between the recuperator outlet and the combustor inlet as shown in Figure 1). The turbine is able to produce $100 \mathrm{~kW}$ electrical power (in grid-connected operations) in nominal conditions with $30 \%$ $( \pm 1 \%$ ) electrical efficiency (nominal rotational speed is 70000 $\mathrm{rpm})$. Although in this paper the vessels are used to perform tests for a general application to all the innovative turbine based systems, the test rig was designed for emulations of fuel cell based hybrid systems [14,20]. For this reason, a modular vessel was installed to represent the cathodic side of a fuel cell and a second tank was included for the anodic side (with a recirculation system based on a single stage ejector) [14]. Since in this work these vessels are used just as additional volume components, no further details are reported as in previous works $[14,20]$.

The modular vessel is based on two collectors connected with four module pipes (Figure 2). These collectors and modules are $0.35 \mathrm{~m}$ diameter pipes for a total length of $34 \mathrm{~m}$ approximately. The second vessel (the anodic one in the "fuel cell emulator") is a fifth $0.35 \mathrm{~m}$ diameter module. The rig is equipped with connection pipes including control valves for flow management. The total volume related to the vessels and these connection pipes (additional to the standard T100 layout) is about $4.1 \mathrm{~m}^{3}$. It is $0.1 \mathrm{~m}^{3}$ higher than the value presented in $[14,20]$ because in these previous works a part of the connection pipes was not accounted as fuel cell volume. Figure 2 shows a general test rig picture and how the three module pipes can be disconnected (the large arrows on the part a) of the figure) to reduce the volume size connected to the microturbine.

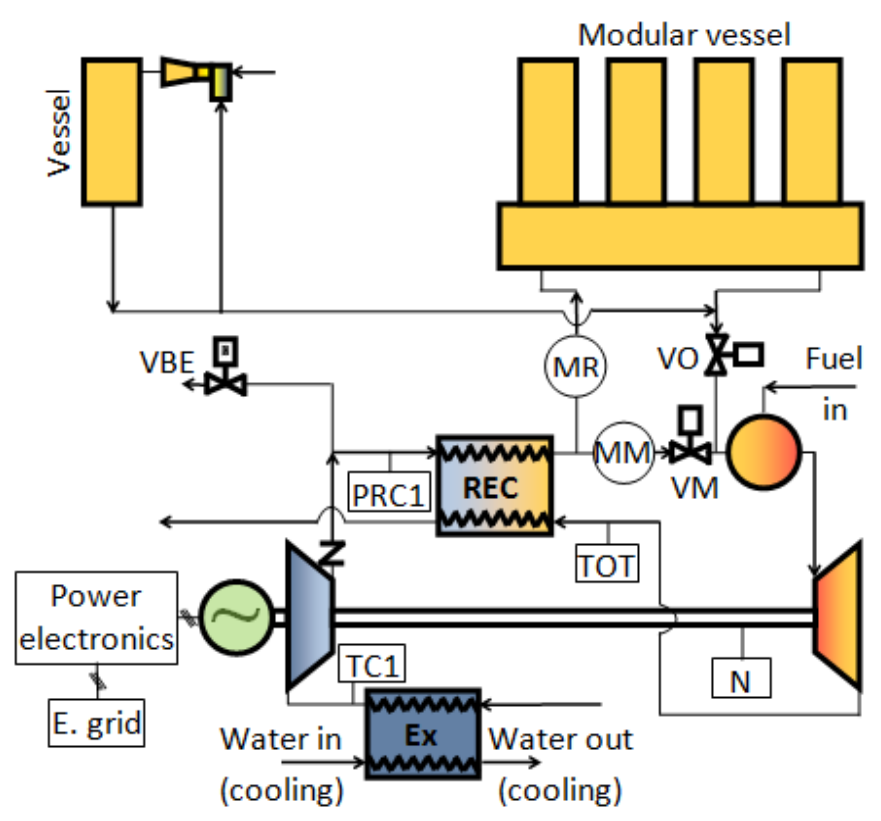

Figure 1. Test rig layout.

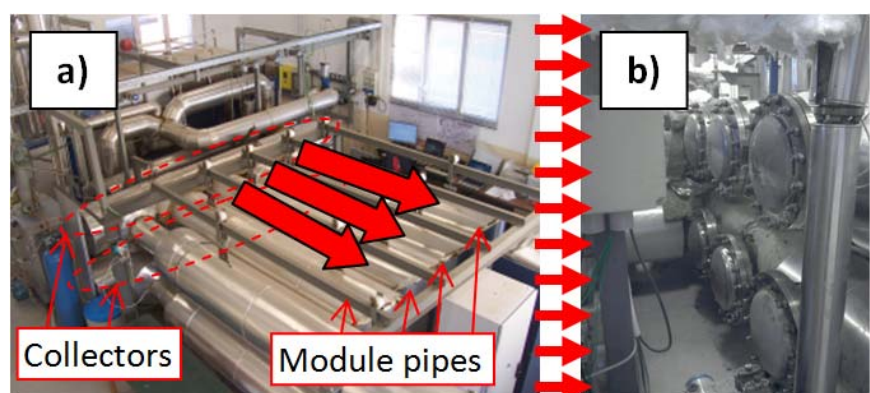

Figure 2. Test rig general picture (a) and removal of three module pipes in the modular vessel (b).

The test rig is also equipped with a check valve downstream of the compressor outlet and with the following main control valves: to manage the connection with the modular vessel (VM, and VO) and to discharge a part of the air flow through bleed operations (VBE is an on/off emergency valve).

The test rig is operated through a data acquisition and control system developed in LabVIEW $^{\mathrm{TM}}$ environment. It includes the data operations on all the probes installed to measure mass flow rate, pressure and temperature in the ducts. 
While Figure 1 shows just the location of the probes used in this paper, more details on all the measurement devices and their accuracy values are reported in previous works $[14,20]$. To ensure safe turbine operation, the original gas turbine control system was maintained without modifications. During load changes, it operates on the fuel flow to maintain the Turbine Outlet Temperature (TOT) value at $918.15 \mathrm{~K}$. The control software developed in $\mathrm{LabVIEW}^{\mathrm{TM}}$ was also equipped with an interface to obtain all the values measured by the turbine system for performance evaluation. In comparison with previous works $[14,20,26]$, where the acquisition time step was equal to $1 \mathrm{~s}$ for all the properties, in these experimental tests this value was reduced to $0.1 \mathrm{~s}$ for the probes able to operate with this requirement.

Since the ambient temperature is very significant for gas turbine operations, an additional system was installed to control the compressor inlet temperature (TC1 in Figure 1). It is composed of three air/water heat exchangers located in the compressor intake ducts (shown with the "Ex" device in Figure 1) used for TC1 control operations through water flow operated in open circuit or cooled by an absorption chiller $[30,31]$.

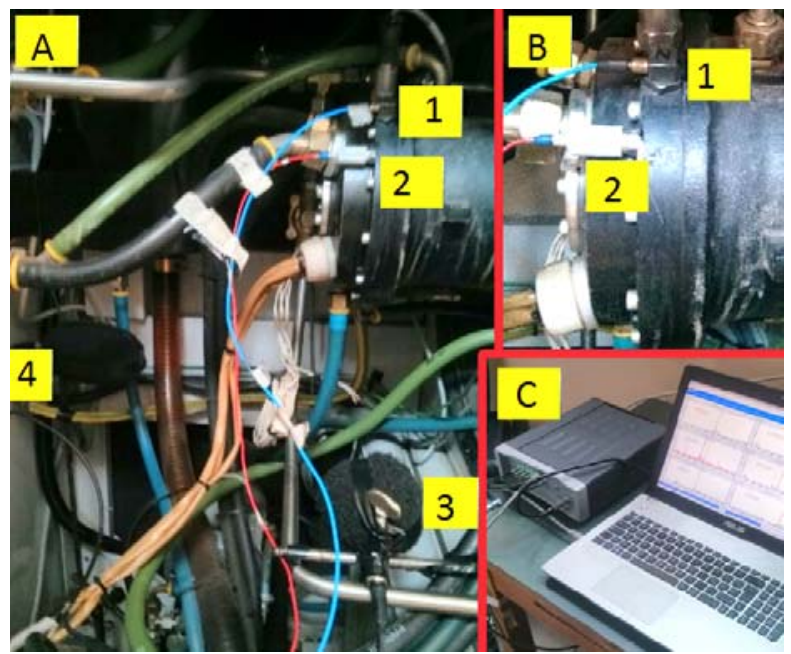

Figure 3. Vibration and acoustic sensor placement on the microturbine: $(A)$ internal vane in the T100 case,

$(B)$ instrumentation installed on the electrical generator, $(C)$ acquisition system for vibration and acoustic data.

Due to the microturbine modifications and the volume temperature and pressure losses the maximum load operating conditions are different from the T100 nominal values (e.g. the microturbine is not able to reach $100 \mathrm{~kW}$ net power). So, the system is able to operate at $73.5 \mathrm{~kW}$ maximum net power at $300 \mathrm{~K}$ compressor inlet temperature with $68300 \mathrm{rpm}$ rotational speed (Turbine Outlet Temperature: $918.15 \mathrm{~K}$ ). In this case, the recuperator outlet pressure (PRC1) was measured equal to 4.1 bar, the recuperator outlet temperature was $875 \mathrm{~K}$, the air mass flow rate (MR) was equal to $0.77 \mathrm{~kg} / \mathrm{s}$, the fuel mass flow rate was $7.8 \mathrm{~g} / \mathrm{s}$ and the losses between recuperator and combustor inlet vanes were $142 \mathrm{mbar}$ and $99 \mathrm{~K}$ for pressure and temperature respectively.

Vibration and acoustic measurements were conducted using a Siemens Scadas mobile data acquisition system (Figure 3 ), which allows to acquire 8 different channels with frequencies up to $204.8 \mathrm{kHz}$ sampling rate per channel, at the same time. Structural measurements were performed using mono and tri-axial accelerometers located on the compressor side of the microturbine on the electric generator case. Sensor dynamic characteristics allowed investigating the frequency signals up to $10 \mathrm{kHz}$. Two micro accelerometers were used in order to extend vibration investigation to the higher frequencies, in the range of blade pass frequency (bpf) phenomena. The first, placed in radial position had a resonance frequency higher than $55 \mathrm{kHz}$, the second, axially oriented had frequency of $80 \mathrm{kHz}$. Acoustic measurements were carried out with a pre-polarized Gras microphone with range between 2 and $50 \mathrm{kHz}$ of dynamic response.

Figure 3 shows the probe placements characterized by a tri-axial sensor (1) with $\mathrm{x}, \mathrm{y}, \mathrm{z}$ axes oriented in the microturbine axial, tangential and radial direction, respectively. Radial (3) and a axial (4) oriented microphones equipped with ellipsoidal windscreen were assembled at the compressor inlet section in order to capture acoustic noise. A mono axial accelerometer (2) with higher amplitude range was used to detect axial vibration signal even during the surge when other accelerometers might saturate. An additional tachometer signal was obtained by a coil wrapped around an output three phase generator wire and was recorded simultaneously with the other signals.

\section{EXPERIMENTAL TESTS}

Three different experimental tests were carried out with the following different additional volume sizes: $4.1 \mathrm{~m}^{3}$ with the entire vessels, $2.3 \mathrm{~m}^{3}$ obtained by removing three module pipes (as shown in Figure 2) and $0.3 \mathrm{~m}^{3}$ obtained by closing all the connection lines between the turbine and the vessels. The 4.1 $\mathrm{m}^{3}$ case is representative of an SOFC based hybrid system $[14,20]$ and the T100 operating in connection with the $2.3 \mathrm{~m}^{3}$ volume is related to a plant including a high temperature storage device (e.g. in a concentrated solar power cycle). The $0.3 \mathrm{~m}^{3}$ volume is representative of the order of magnitude size of a saturator for a micro-hat system [4]. During each test, the volume size effect was analyzed with two different operations: a VBE step closing (from $100 \%$ to $0 \%$ because it is an on/off valve) and the closing of a valve located in the main air path (VO for the tests operated with $4.1 \mathrm{~m}^{3}$ and the $2.3 \mathrm{~m}^{3}$ additional volume and $\mathrm{VM}$ for the $0.3 \mathrm{~m}^{3}$ case). Due to the importance of ambient temperature on turbine performance, in all cases the $\mathrm{TC} 1$ temperature was maintained at $300 \mathrm{~K}( \pm 0.1 \mathrm{~K})$ by an open circuit water flow.

These two operations were carried out to analyze the different volume effects during transient phases. Since the load change is managed slowly (about $100 \mathrm{~s}$ for a $10 \mathrm{~kW}$ step) by the standard turbine control system, no specific transient effect 
(due to volume size) is present. Operations on valves are necessary for this transient analysis purpose. Due to the importance of surge prevention during operations with innovative plants including large volume devices, the tests were carried out focusing attention on surge risks and precursors. For this reason, the VBE step was carried out to show surge risk increase due to volume increase. The analysis was completed generating real surge conditions (closing a valve located in the main air path) to define possible surge precursors to be collected by standard probes for control system operations. The volume size effect is discussed considering the precursors to be used for possible control applications and solutions.

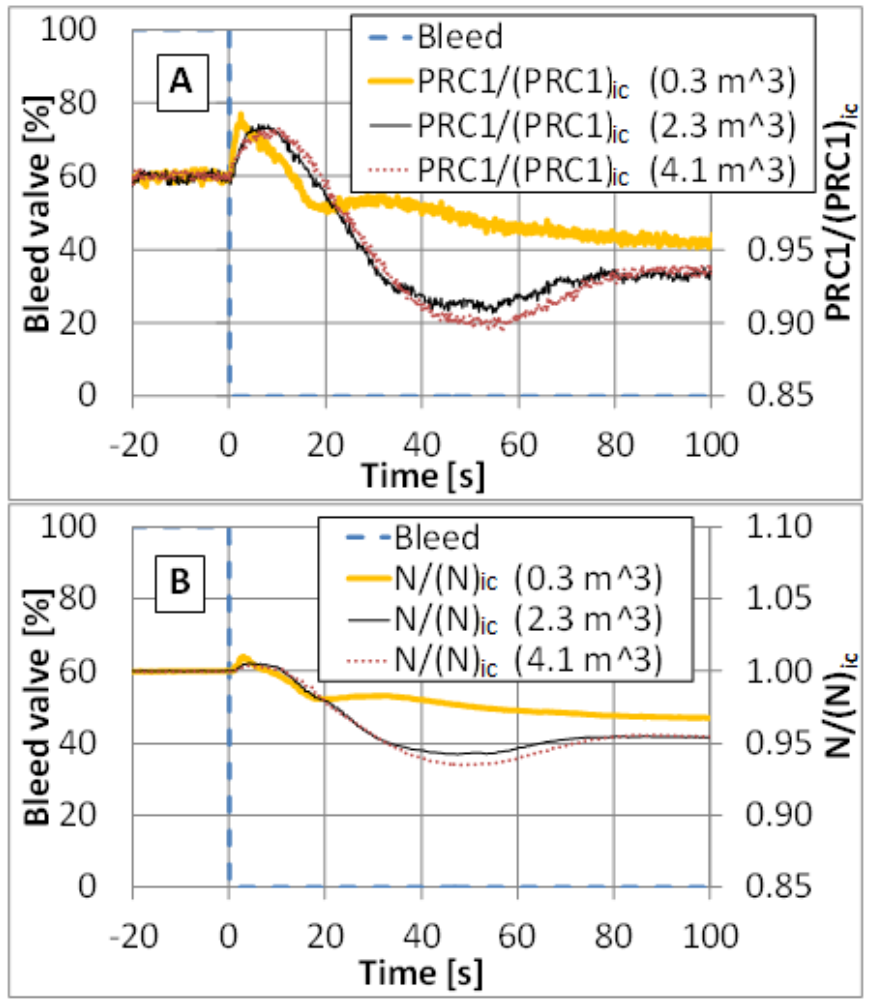

Figure 4. VBE closing step: recuperator inlet pressure $(A)$ and rotational speed (B).

\section{EXPERIMENTAL RESULTS: VBE STEP}

These tests were carried out to show the different transient responses due to the T100 coupled with different additional volume sizes. All the three tests were started from steady-state condition with the microturbine producing $40 \mathrm{~kW}$ electrical load and $0.06 \mathrm{~kg} / \mathrm{s}$ discharged mass flow rate through the VBE valve. This initial condition was selected considering the following purposes: significant off-design condition (usually these advanced systems need to be very flexible in terms of part-load operations), initial condition with a large margin from surge, avoidance of too low load values where the machine control system reduces the Turbine Outlet Temperature (TOT) set-point to decrease the surge risk, and a feasible initial condition with the plant equipment (e.g. the VBE size). The values of the main properties related to these initial steady-state conditions ("ic" subscript) are reported in Table 1 for the different volume sizes.

Table 1. Initial condition values (subscript "ic") for the VBE step test.

\begin{tabular}{|l|c|c|c|}
\hline & $4.1 \mathrm{~m}^{3}$ & $2.3 \mathrm{~m}^{3}$ & $0.3 \mathrm{~m}^{3}$ \\
\hline PRC1 [bar] & 3.40 & 3.42 & 3.27 \\
\hline $\mathrm{N}[\mathrm{rpm}]$ & 62805 & 62926 & 61637 \\
\hline Air mass flow rate [kg/s] & 0.59 & 0.59 & 0.53 \\
\hline Pressure loss [mbar] & 178 & 180 & 116 \\
\hline TOT [K] & 918.15 & 918.15 & 918.15 \\
\hline Net power [kW] & 40.0 & 40.0 & 40.0 \\
\hline Kp [-] & 1.19 & 1.18 & 1.11 \\
\hline
\end{tabular}

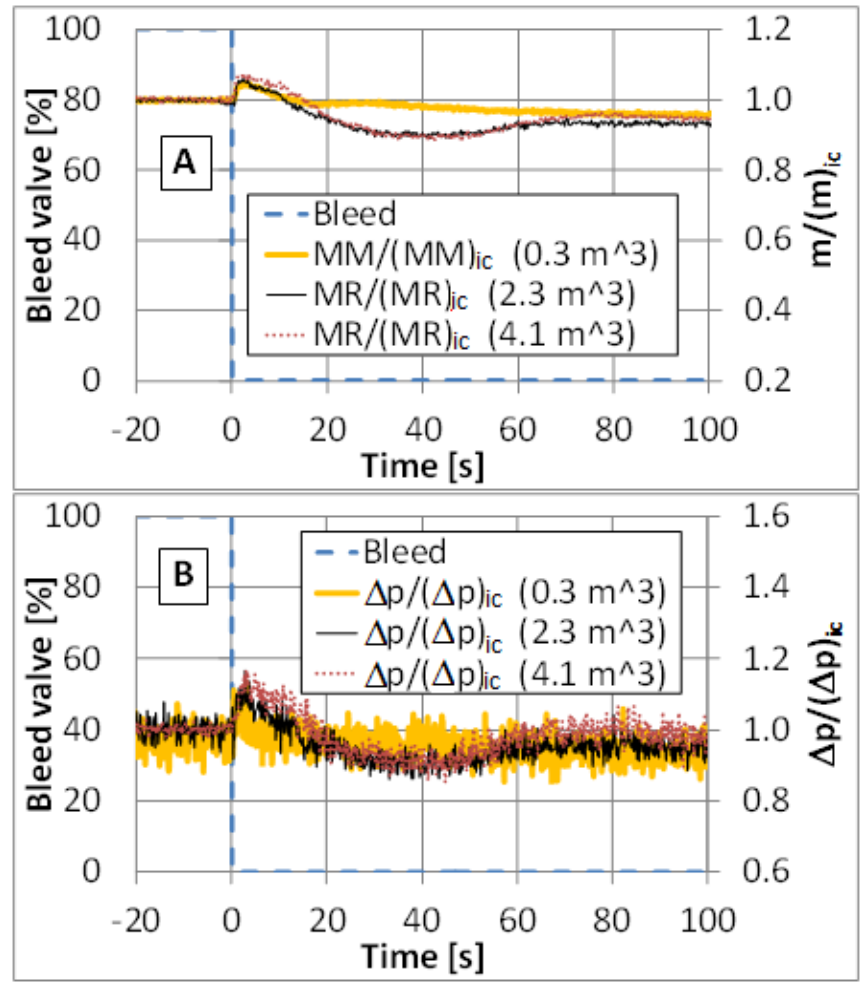

Figure 5. VBE closing step: combustor inlet mass flow rate $(A)$ and pressure losses between the recuperator and the combustor inlet ducts $(B)$.

As shown in Figure 4, at time zero the VBE was closed with a step (it is an on/off valve). This operation was able to generate a pressure peak (PRC1 in Figure 4 - part A) showing the transient response of the system. This VBE closing step was selected (instead of a load step) to analyze the different transient responses of the machine with the different volume sizes. No load changes were analyzed because the T100 transient response is mainly driven by the control system. Since 
(in case of load changes) it operates slowly (about $100 \mathrm{~s}$ for 10 $\mathrm{kW}$ steps) the volume size transient effect is smoothed.

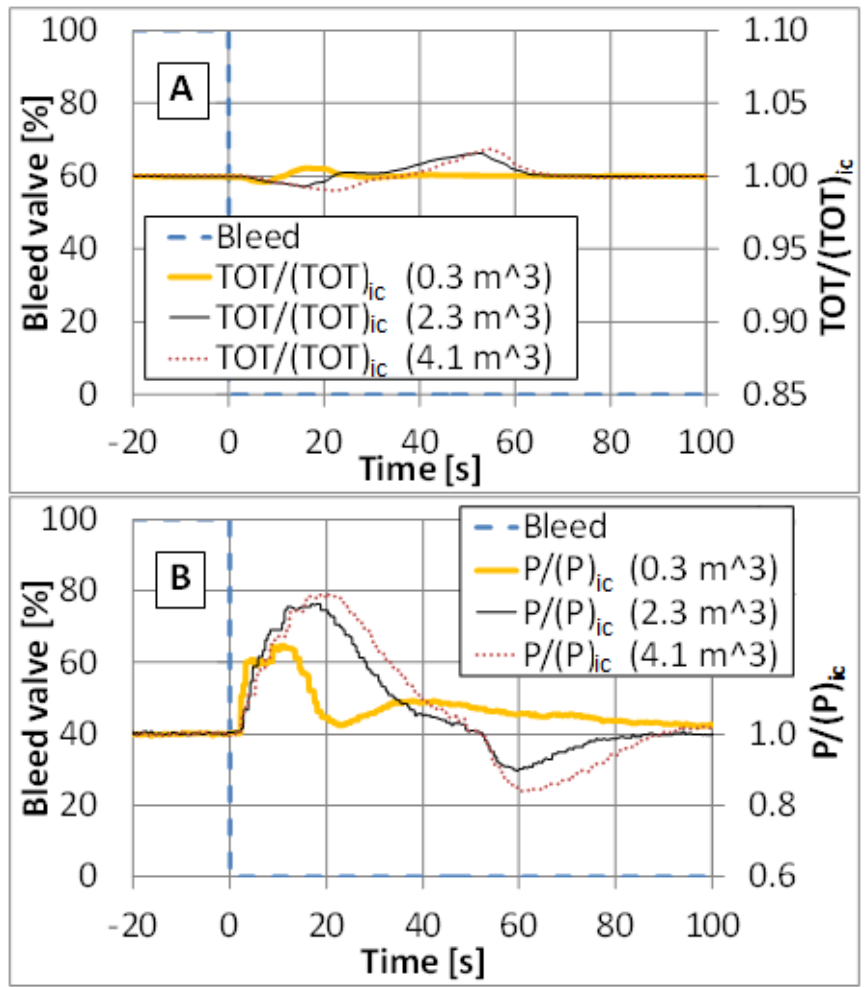

Figure 6. VBE closing step: TOT (A) and net electrical power (B).

The steady-state pressure values obtained before the VBE closing steps are: 3.40 bar, 3.42 bar, 3.27 bar with $4.1 \mathrm{~m}^{3}, 2.3$ $\mathrm{m}^{3}, 0.3 \mathrm{~m}^{3}$, respectively. No significant difference is obtained between the $4.1 \mathrm{~m}^{3}$ and the $2.3 \mathrm{~m}^{3}$ cases, because the removal of the three module pipes (shown in Figure 2) is not generating a significant pressure loss increase (2 mbar over 178 mbar). However, for the $0.3 \mathrm{~m}^{3}$ test Table 1 shows a lower PRC1 value at the initial steady-state condition. This effect is due to the decrease in rotational speed (to obtain the same generated power) that is mainly related to the decrease in pressure loss (significant removal of the vessel additional pipes). Moving from the maximum to the minimum additional volume size, Figure 4 shows different peak time values: $10.1 \mathrm{~s}$ for $4.1 \mathrm{~m}^{3}$, $7.8 \mathrm{~s}$ for $2.3 \mathrm{~m}^{3}$ and $2.3 \mathrm{~s}$ for $0.3 \mathrm{~m}^{3}$. While the PRC1 transient trends are significantly driven by the rotational speed trends (Figure 4 - part B), the volume size effect is shown by the pressure peak delays (about $7 \mathrm{~s}, 2 \mathrm{~s}$ and negligible for $4.1 \mathrm{~m}^{3}$, $2.3 \mathrm{~m}^{3}, 0.3 \mathrm{~m}^{3}$, respectively) from the related rotational speed peak.

Figure 5 shows the direct consequence of the rotational speed: the air mass flow rate (measured with two different probes due to two different layouts) and the global pressure drop between the recuperator outlet and the combustor inlet.
Both properties are mainly following the rotational speed trend, even if few differences in the peak time locations are present due to the pressure-rotational speed link in the compressor performance maps.

The delay effect related to the volume size is shown also by the TOT that is maintained constant by the turbine controller. However, limited oscillations are present showing significant delay increase (Figure 6 - part A) with the volume increase. This effect is also significant in the trend of the net electrical power (Figure 6 - part B) produced by the microturbine. While the controller was able to recover the 40 $\mathrm{kW}$ condition, a significant oscillation was generated in all cases. After the bleed valve closing step and about $1 \mathrm{~s}$ dead time, the power increased due to the sudden increase in mass flow rate. Then, an oscillation was generated due the control system response that managed the fuel valves.

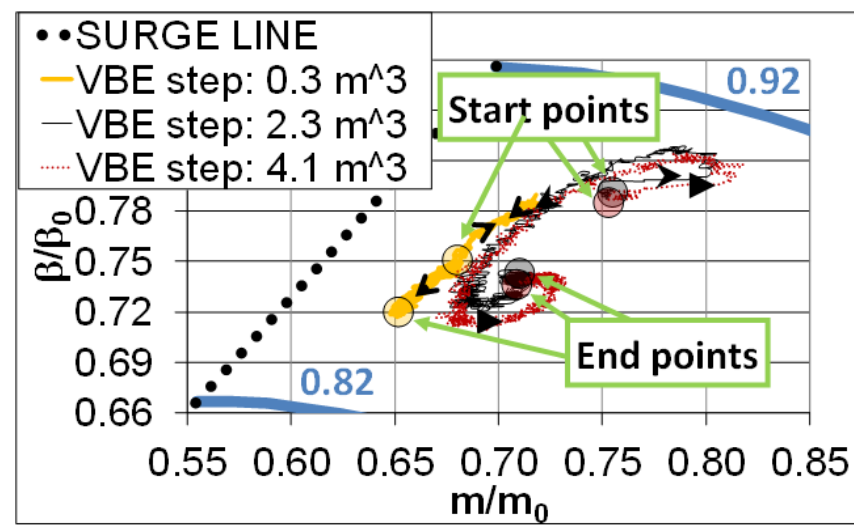

Figure 7. VBE closing step: transient operation on the compressor map (each compressor curve is plotted for the same $N / N_{0}$ value).

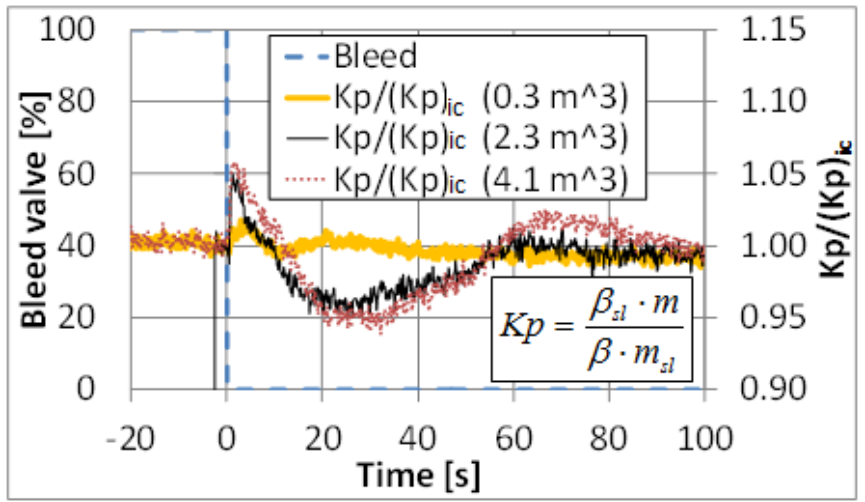

Figure 8. VBE closing step: surge margin.

These tests are also represented on the compressor map (Figure 7). While the trend is almost linear for the $0.3 \mathrm{~m}^{3}$ test, the volume increase generates a sort of "hook" path that is more evident with the largest volume size. So, a significant surge margin decrease during this transient operation is shown by Figure 7 and 8 . This effect is significantly amplified by the 
volume size (the highest surge margin decrease during the transient operation is related to the $4.1 \mathrm{~m}^{3}$ case). In detail, Figure 8 shows that large volume layouts, even operating with high surge margin condition in steady-state mode, could be critical in case of more intensive similar operations. This aspect needs to be carefully taken into account by the control system for the real reference plant.
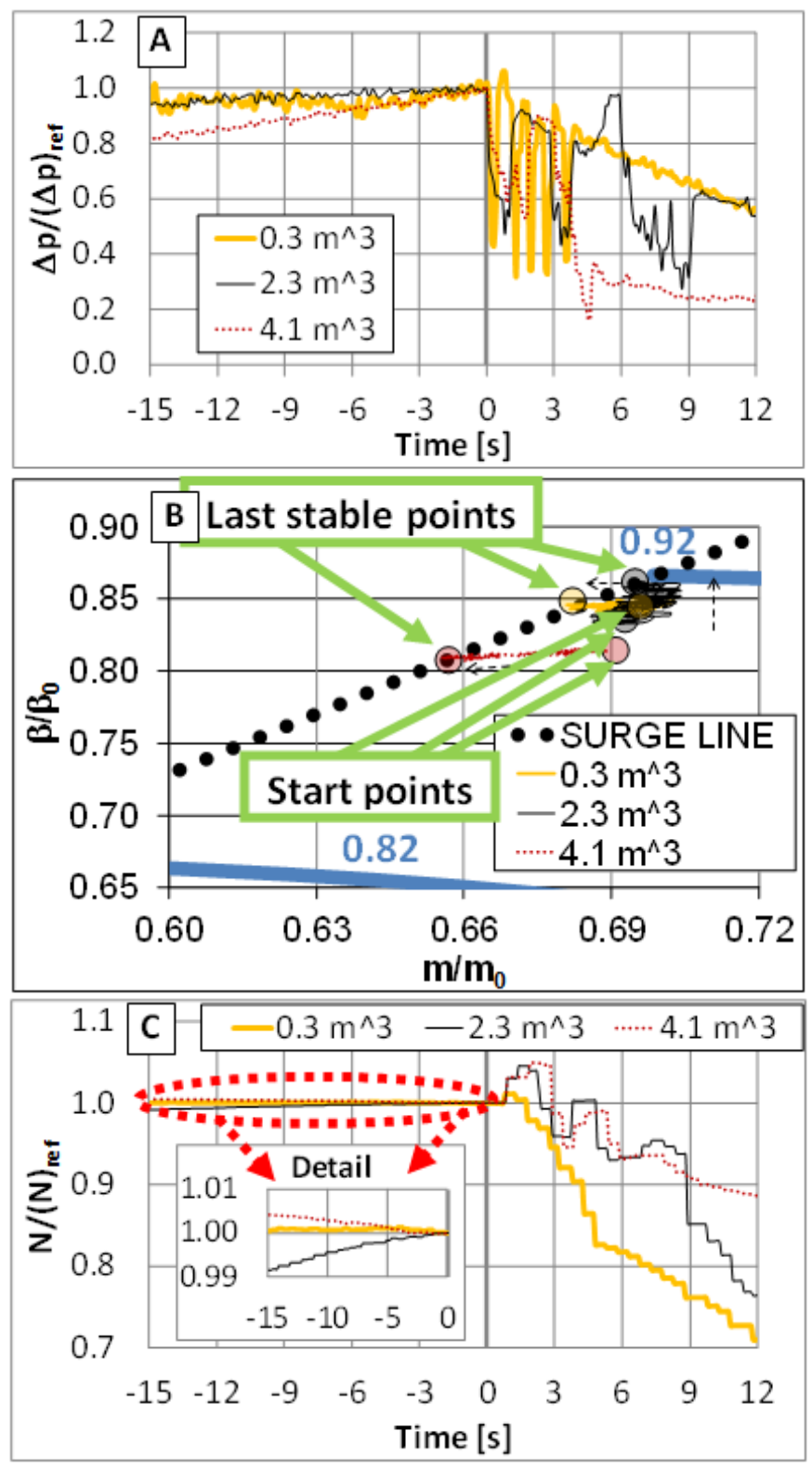

Figure 9. Main line valve closing: pressure losses between the recuperator and the combustor inlet ducts (A), surge approaching on the compressor map (each compressor curve is plotted for the same $N / N_{0}$ value) (B) and rotational speed (C).

\section{EXPERIMENTAL RESULTS: MAIN LINE VALVE CLOSING}

The results reported here are related to a second series of tests carried out with different volume sizes. Also in this case, the microturbine was operated in grid-connected mode with the variable speed control system (the TOT value is maintained constant at its set-point $(918.15 \mathrm{~K})$ up to the surge events by changing the fuel mass flow rate). While in the VBE step tests Figure 8 shows an increased surge risk in transient mode (due to large volume operations), this section presents results related to real surge operations and prevention techniques. These tests were carried out to generate surge conditions closing a valve located in the air path (between the recuperator outlet and the combustor inlet). This operation generated a significant increase in pressure loss and, as a consequence in PRC1 also, leading the turbine to the surge zone. The values of the main properties related to the surge limit (last stable measured points) are reported in Table 2 for the different volume sizes ("ref" subscript).

Table 2. Last stable measured values (subscript "ref") for the main line valve closing test.

\begin{tabular}{|l|c|c|c|}
\hline & $4.1 \mathrm{~m}^{3}$ & $2.3 \mathrm{~m}^{3}$ & $0.3 \mathrm{~m}^{3}$ \\
\hline Pressure loss [mbar] & 611 & 520 & 457 \\
\hline $\mathrm{N}$ [rpm] & 62021 & 64426 & 63681 \\
\hline Net power [kW] & 20.0 & 35.2 & 39.1 \\
\hline Air mass flow rate [kg/s] & 0.51 & 0.54 & 0.53 \\
\hline PRC1 [bar] & 3.50 & 3.73 & 3.66 \\
\hline TOT [K] & 918.15 & 918.15 & 918.15 \\
\hline Kp [-] & 1.00 & 1.00 & 1.00 \\
\hline
\end{tabular}

Figure 9 (part A) shows the pressure loss (between recuperator and combustor chamber inlet ducts) that was increased by the main valve gradual closing operation. Then, the effect of the surge events (happening at time zero for all cases) is shown by the pressure drop oscillations. Table 2 shows a significant difference between the pressure loss values necessary to reach the surge line. This is due to the different paths (shown on the compressor map by Figure 9 - part B) that were followed by the operating points to reach surge conditions. To better discuss this aspect, Figure 9 (part B) shows a comparison between the different volume cases. Even if the $4.1 \mathrm{~m}^{3}$ and the $2.3 \mathrm{~m}^{3}$ cases were very similar at steadystate conditions (see Table 1), the differences related to transient operations were responsible for significant differences in the last stable point values: while in the $4.1 \mathrm{~m}^{3}$ test a 611 mbar pressure drop was necessary to reach the surge line because the rotational speed was decreasing (Figure 9 - part C), in the $2.3 \mathrm{~m}^{3}$ test the rotational speed increase moved the system directly to surge with a direct path. For this reason, the pressure loss necessary to reach the last stable point was significantly lower $(520 \mathrm{mbar})$. The path related to the $0.3 \mathrm{~m}^{3}$ case was an intermediate behavior between the other volume size tests (the rotational speed was almost constant approaching the surge line). So, no high increase in pressure drop was 
necessary: the last stable value was 457 mbar. In comparison with the $2.3 \mathrm{~m}^{3}$ test case, this pressure drop is lower for the lower value of the rotational speed.

To complete the presentation of the input condition, Figure 10 presents the net electrical power produced by the turbine (negative values represent electrical power absorbed by the grid for the auxiliary components). Due to critical thresholds in the electrical power conditioning system (constraints on the direct current bar voltage implemented in the Turbec standard control system), it was not possible to maintain the $40 \mathrm{~kW}$ load in all cases. Especially during the $4.1 \mathrm{~m}^{3}$ test, the $\mathrm{VO}$ valve closing produced significant power decay down to $20 \mathrm{~kW}$. Even if all the three tests were started with the microturbine load set-point at $40 \mathrm{~kW}$, it was not possible to produce the three surge events (with the three different volume sizes) at the same initial condition. However, the experimental results presented in this section are significant to show the volume size effect during transient operations and to find surge precursors for control system application (in agreement with the purpose of this work).

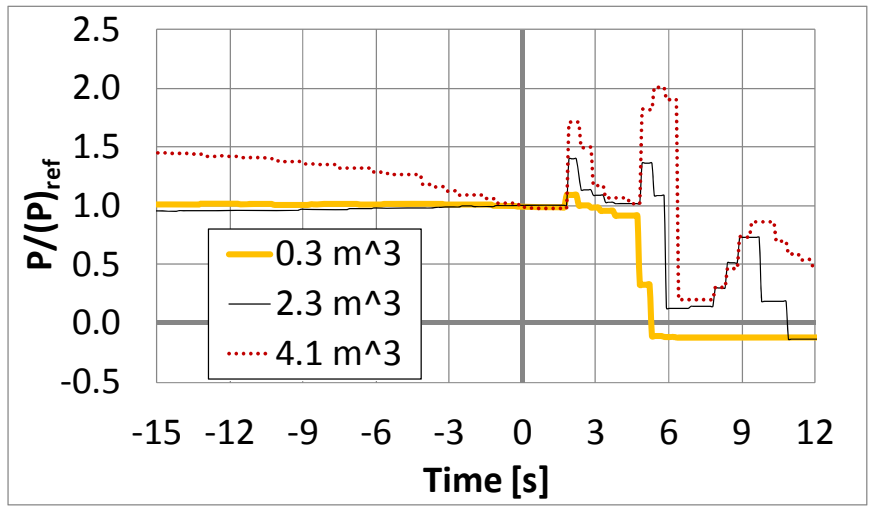

Figure 10. Main line valve closing: net electrical power.

From the transient point of view, Figure 10 is able to show oscillations due to surge event in case of low frequency phenomena (constraint of the electrical power sensor installed in the commercial T100 turbine). For this reason, while in the $4.1 \mathrm{~m}^{3}$ and in the $2.3 \mathrm{~m}^{3}$ cases power oscillations are visible, the oscillations related to the $0.3 \mathrm{~m}^{3}$ test are completely smoothed.

The transient effects of surge events can be better discussed considering the combustor inlet mass flow rate (Figure 11 - part A) and the recuperator inlet pressure (PRC1) at the cold side inlet (Figure 11 - part B). Both properties are able to highlight the volume effect in terms of oscillation frequency (from $0.4 \mathrm{~Hz}$ with $4.1 \mathrm{~m}^{3}$ additional volume to 1.3 $\mathrm{Hz}$ for the $0.3 \mathrm{~m}^{3}$ case). Due to the high rotational speed and large volume values, in this case, it is not possible to calculate these frequency values with the Helmholtz equation [32]. Since a comparison with the theoretical frequency values (as shown in [32]) is not possible, the experimental measurements have a further relevant significance. Moreover, the effect of the additional volume size is also visible in the PRC1 values after the oscillations due to surge conditions. With higher volume size pressure tends to remain high for longer periods.

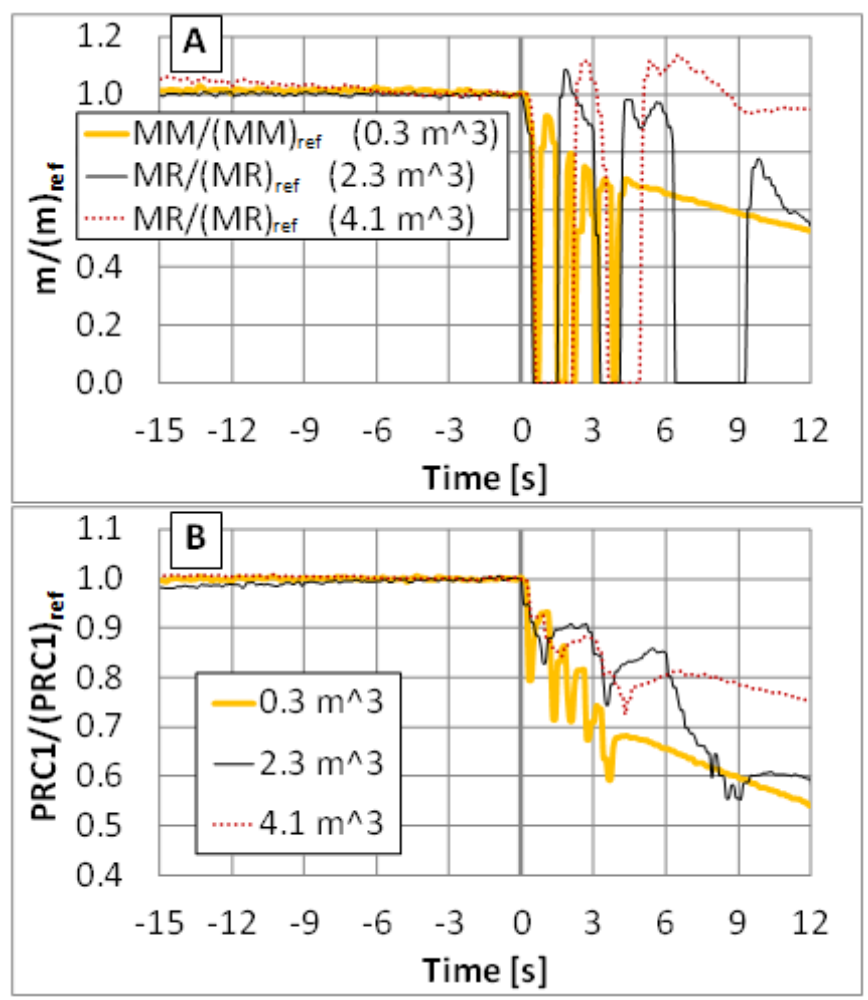

Figure 11. Main line valve closing: combustor inlet mass flow rate $(A)$ and recuperator inlet pressure (B).

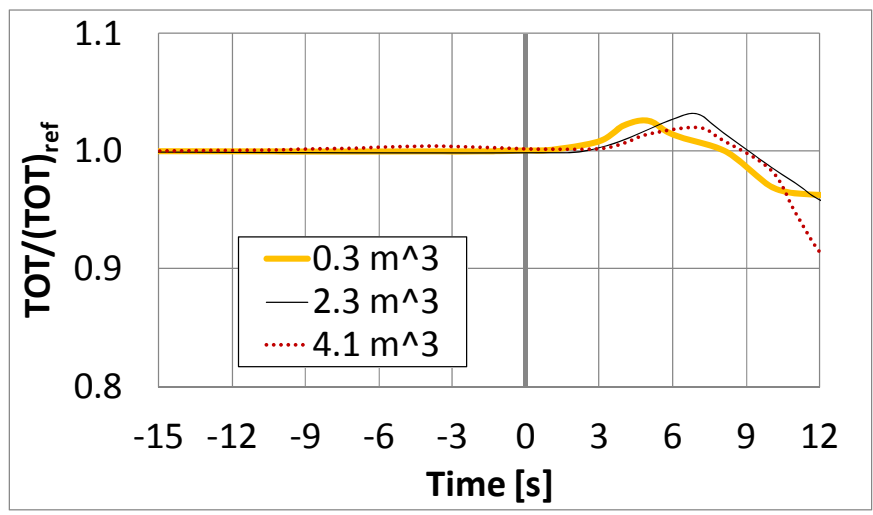

Figure 12. Main line valve closing: TOT.

Figure 12 shows the TOT values during these surge events. The mass flow rate behavior (it is reduced to zero for few fractions of second during surge) generated a significant (and dangerous) TOT peak. For this reason, the T100 control system operated the machine shutdown, as shown by the fast rotational speed decrease after 6-9 s from the surge events. A smoothed 
delay effect due to the volume size is also visible in the TOT curves (Figure 12).

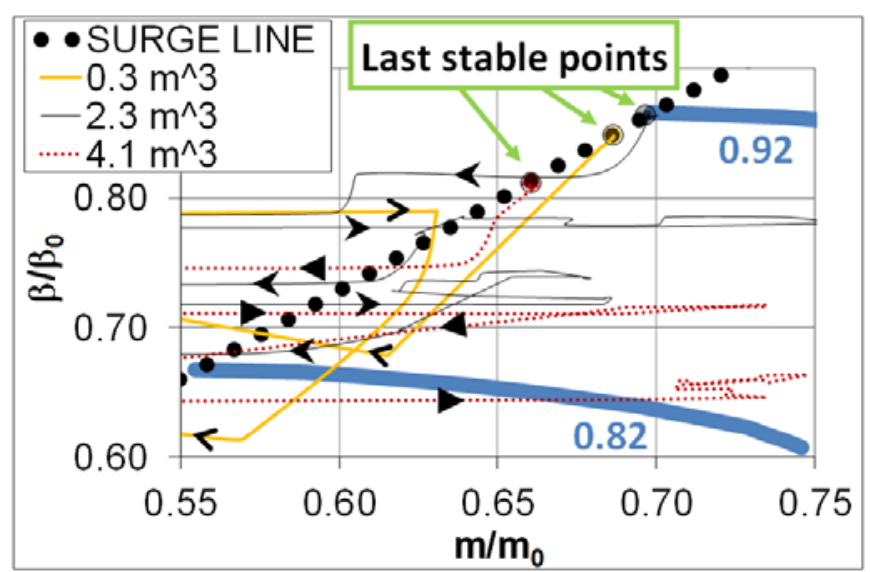

Figure 13. Main line valve closing: surge events on the compressor map (each compressor curve is plotted for the same $\mathrm{N} / \mathrm{N}_{0}$ value).

The representation of these surge events is completed with the operating lines plotted (Figure 13) on the compressor map (measured by the T100 manufacturer). No negative mass flow values are present due to the check valve installed downstream of the compressor (Figure 1). The most significant results shown by Figure 13 are the start points of the surge events. These are the last stable operating points before the surge events obtained by closing the valve in the air main line. They tend to be on the surge limit curve for all the cases without any specific volume size effect.

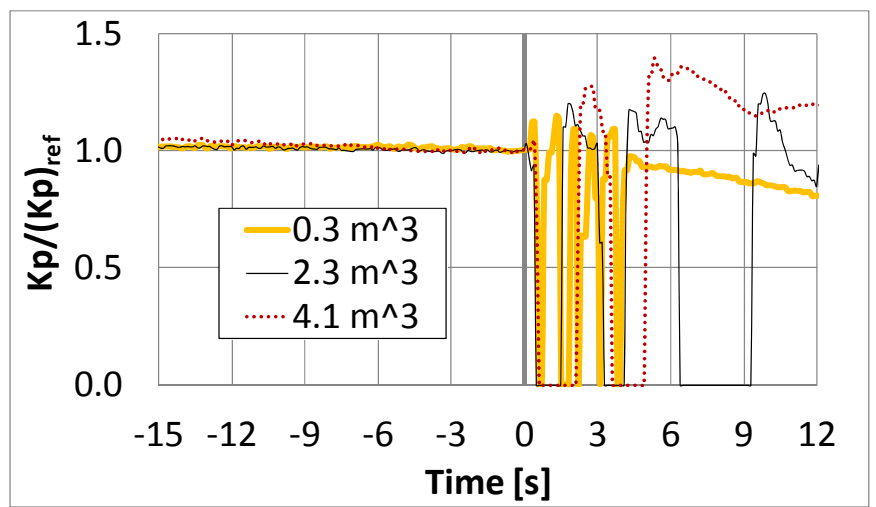

Figure 14. Main line valve closing: surge margin.

Since in Figure 13 the paths are not completely clear because the curves are superimposed or crossed for several times, Figure 14 completes the description of the surge events showing the compressor surge margin. The calculation of this parameter is based on the equation in Figure 8. As discussed for PRC1 and air mass flow rate, also the surge margin plots are able to show the volume size effect.

\section{Vibration and acoustic analysis}

These tests were carried out to evaluate how vibration structural response and acoustic (operating noise radiated by the machinery) aspects could be used to detect the inception of the surge. The results shown here will be essential for control system development including improvements on surge prevention. For this purpose, trends and spectra of the accelerometer signals were analyzed during this transient operation. During the tests already presented in Figures 9-14, the compressor operating condition was changed from a stable working point to the surge during the main line closing tests. During these tests the additional tachometer signal was acquired synchronously with the other signal sensors. Due to the complexity of the analysis, it was not possible to align all the data putting time zero on the surge event (as shown in Figures 9-14). However, the surge event is clearly shown for all the cases, even if they are based on a different initial time value. During the transient operation of surge approaching, the machinery changed its rotational speed keeping it in the range between $62000 \mathrm{rpm}$ and $65000 \mathrm{rpm}$. Speed value determines the lower sampling rate limit of the signals, because previous studies revealed the importance of the entire sub-synchronous frequency range in order to detect the inception of the surge event [33].

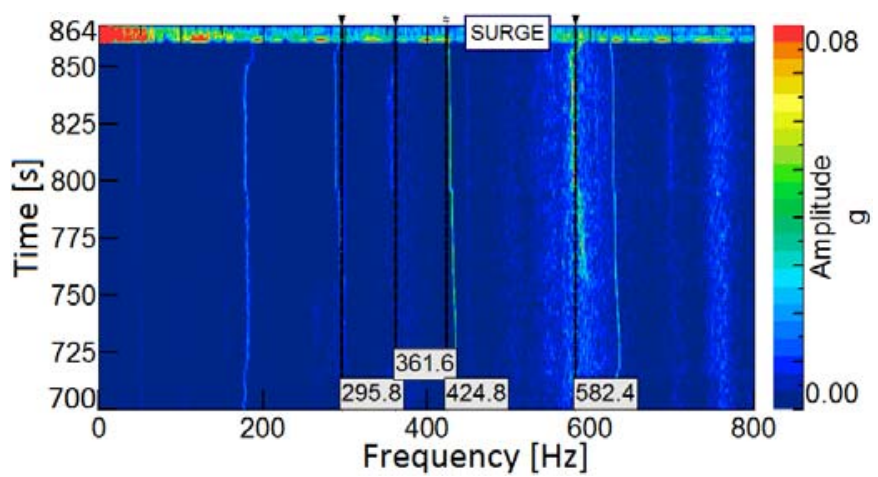

Figure 15. Main line valve closing: vibration time frequency analysis during surge transient (zoomed map).

A sampling rate of $8196 \mathrm{~Hz}$ was chosen for the acquisitions because of its capacity to contain all significant frequencies. Only for the micro-accelerometer signal, a different sampling rate up to $200 \mathrm{kHz}$ was adopted to examine the range around the bpf. Vibration analyses were executed in all the different plant conditions characterized by various abovementioned volumes. Different types of analyses were conducted on acquired signals to find a signal transformation or elaboration with a high sensitivity to the approaching surge.

Initially, the frequency analysis was conducted to evaluate the change of the signal frequency spectrum while the surge condition was progressively approaching. The time-frequency analysis underlines that sub-synchronous content seems to be more significant for the identification of the surge incipit, as 
shown in literature [32,33]. Figure 15 shows the timefrequency analysis through zoomed color-map representation of axial vibration component (in the case of $4.1 \mathrm{~m}^{3}$ ), measured on the compressor by the tri-axial accelerometer. This analysis allows determining which frequency components show an important modification and a possible energy increase before the surge condition (it was reached on the top of Figure 15).

From the color-map analysis, it is possible to highlight the presence of some frequency components, which shows a significant modification and intensity variation (with continuity) during the progressive transient operation toward the surge condition. It is possible to assume that each of them is linked to a physical phenomenon that creates vibrations with a specific frequency. This frequency changes during the transient event with a high rotational speed sensitivity. Once the frequency components, that seem to be the most significant ones were revealed, this information was used to filter the acquired signals and then calculate their Root Mean Square (RMS) values.

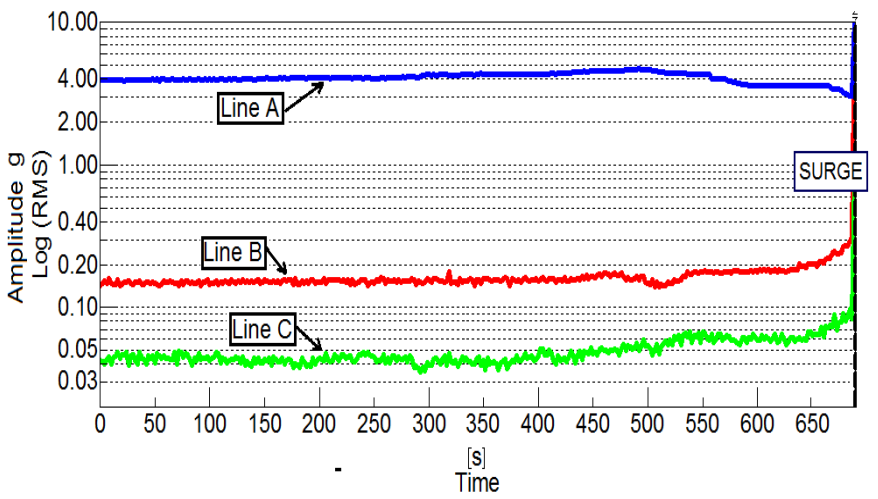

Figure 16. Main line valve closing: RMS values vs time in surge approaching for the over-all signal (line

A), the sub-synchronous content (line B) and a specific sub-synchronous band between $550 \mathrm{~Hz}$ and the $650 \mathrm{~Hz}$ (line C).

Bands ranges used to filter the data were chosen in order to consider just the above mentioned frequency variations. Frequency contents of accelerometer signals in the three directions are not necessarily the same. Moreover, some frequency contents, with a significant amplitude for more axes, do not have the same intensity and a relevant increase in energy content in all axes close to the surge condition. The $\mathrm{X}$ axial direction presented higher interest in comparison with the other axis because it includes more frequency contents which increase their energy (RMS) before the surge event.

Figure 16 shows the RMS value trends for the vibration of the $\mathrm{X}$ component during the transient event in the $4.1 \mathrm{~m}^{3}$ case: for the unfiltered signal (over-all signal named Line A), the only sub-synchronous content (Line B) and a specific subsynchronous band between $550 \mathrm{~Hz}$ and the $650 \mathrm{~Hz}$ (Line C).

The filtered signals show an evident increment of the RMS value approaching the surge condition, while the over-all signal seems to have less sensitivity with an opposite trend in comparison with the previous ones.

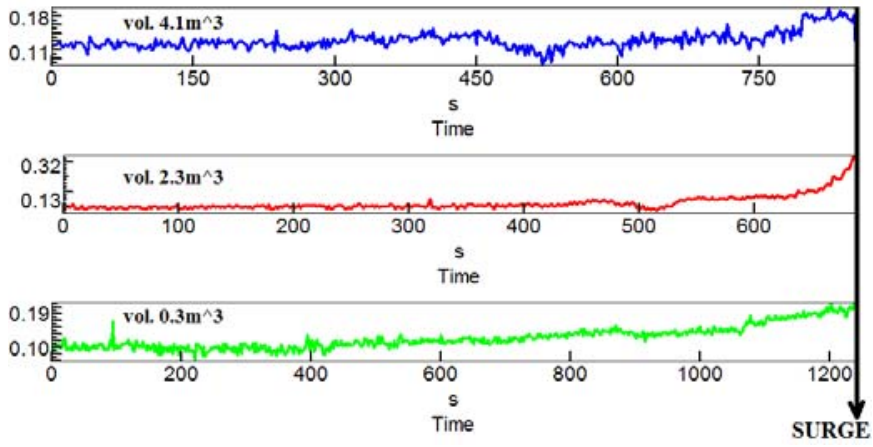

Figure 17. Main line valve closing: sub-synchronous signal trends of the axial accelerometer component for different values of the additional volume.

From this analysis, it is possible to state that filtered values are more interesting than the entire frequency field because they present a significant increase before the surge, while the over-all value has a different behavior which also changes varying volume size configurations. To generalize the surge identification, it seems preferable to use the entire subsynchronous content than a specific band content, which could significantly change depending on the type of plant characteristics. Some specific band contents, increasing before the surge with a volume size, are less sensitive in the other cases.
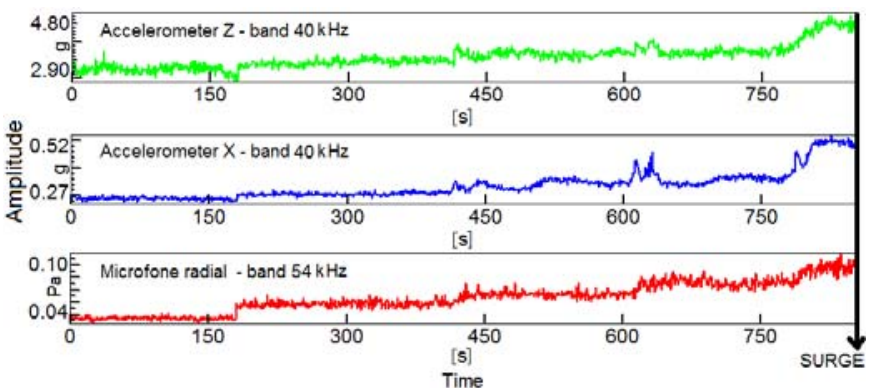

Figure 18. Main line valve closing: $40 \mathrm{kHz}$ signal trends of the high frequency radial (Z), axial (X) accelerometers and $54 \mathrm{kHz}$ signal trend of the microphone.

The RMS sub-synchronous rate is analyzed for the different plant configurations, changing the additional volume size for the same kind of transient event with $4.1 \mathrm{~m}^{3}, 2.3 \mathrm{~m}^{3}$ and $0.3 \mathrm{~m}^{3}$ respectively.

Figure 17 shows that this RMS sub-synchronous rate is increasing in all the three instances, but the intermediate case (2.3 $\mathrm{m}^{3}$ additional volume) seems to show the highest sensitivity, since its values close to the surge are $30 \%$ higher than in the other cases. This could be due to the plant 
characteristics that mainly amplify the surge approaching phenomenon response in particular conditions.

During the transitory to the incipient surge, for the $2.3 \mathrm{~m}^{3}$ volume configuration, acoustic and vibration responses were investigated in correspondence of frequency bands containing bpf superior orders. However, no significant volume size effect seemed to be present at so high frequency values. In Figure 18 energy trends of accelerometer signals acquired using sensor with appropriate dynamic characteristic are reported. In detail, the figure refers to accelerometers positioned in radial and axial direction and the frequency band shown is the third order of the bpf. In the same figure the forth order of the bpf trend from the microphone is presented. These trends are characterized by a good sensitivity as they increase near the incipient surge. This behavior may be related to the flow alteration in the blade channel which influences high frequency vibration response.
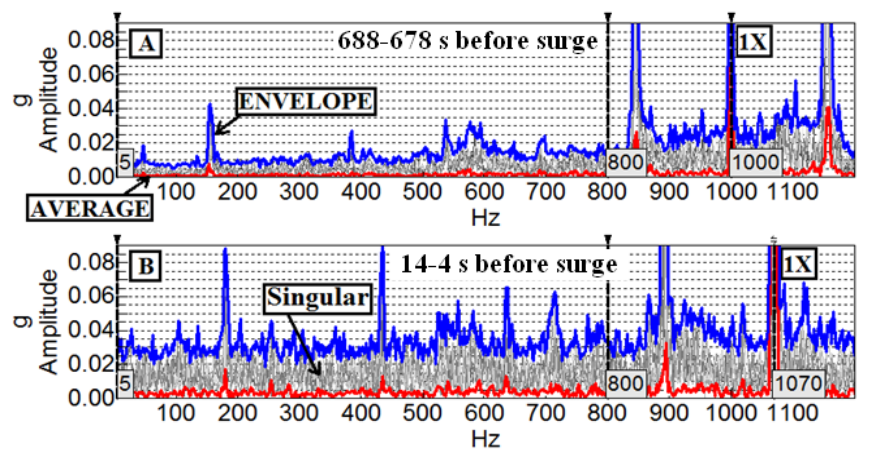

Figure 19. Main line valve closing: sub-synchronous, average and envelope vibrational spectrum far from the surge $(A)$ and few instants before reaching surge

(B) in axial direction for a configuration with an additional volume equal to $2.3 \mathrm{~m}^{3}$ (1X indicates the synchronous frequency in both cases).

In second phase, a further analysis was carried out to evaluate if the system vibration response diverged from a stationary condition when it progressively approaches to the beginning of the surge event. For this purpose, sets of a significant number of spectra (21) were calculated temporally far $(700 \mathrm{~s})$ and close $(1 \mathrm{~s})$ to the surge event. Each spectrum was evaluated from a consecutive extract of the signal corresponding to an interval of time of $0.5 \mathrm{~s}$. These limited intervals of time are still useful to generate a frequency spectrum of sufficient resolution. Every series of spectra may be considered important to characterize the compressor operational vibration response during its total observation time of $10 \mathrm{~s}$.

Starting from the obtained spectra, initial attention was focused on the average spectrum to have an average energy indication of the vibration level for the whole observation time (where the entire singular spectrum was calculated). Then, envelope spectrum was calculated: it allows highlighting the maximum values for each frequency component among the entire spectra set. The difference between these two curves may be considered significant to detect the loss of stationary response for compressor vibrations. This behavior appears in the results reported in Figure 19 related to the test carried out with an additional volume value of $2.3 \mathrm{~m}^{3}$. Similar results were obtained in the other configurations too. In Figure 19 the singular spectra are compared with the average and envelope spectra. The upper and lower graphs refer to a compressor stable condition far (688-678 s) from surge operations and another condition 14-4 s before reaching the surge event, respectively.

In these two conditions, the envelope functions appear different in amplitude for the considered frequency interval corresponding to the whole sub-synchronous field. In detail, the envelope spectrum, calculated using the data acquired close to the surge condition, presents higher marked amplitudes. This result could be justified by considering that as compressor operation condition gets closer to an incipient surge state, significant random and non-deterministic components appear in the vibration response. This result justifies the marked increase of the envelope spectrum in comparison with the average spectrum. Probably, this effect could be related to a nonnegligible dispersion in the singular spectra.

Table 3. Main line valve closing: envelope and variance sub-synchronous spectra RMS values with different additional volume sizes (time intervals from surge events: "Far" means $700 \mathrm{~s}$, "Intermediate" is $300 \mathrm{~s}$, "Near" is $100 \mathrm{~s}$, and "Nearest" is for $1 \mathrm{~s}$ before surge).

\begin{tabular}{|l|c|c|c|c|c|c|}
\hline & $\begin{array}{c}\text { RMS } \\
\text { env. } \\
4.1 \mathrm{~m}^{3}\end{array}$ & $\begin{array}{c}\text { RMS } \\
\sigma\end{array}$ & $\begin{array}{c}\text { RMS } \\
\text { env. }\end{array}$ & $\begin{array}{c}\text { RMS } \\
\sigma\end{array}$ & $\begin{array}{c}\text { RMS } \\
\text { env. }\end{array}$ & $\begin{array}{c}\text { RMS } \\
\sigma\end{array}$ \\
\hline Far & 0.160 & 0.044 & 0.155 & 0.042 & 0.166 & 0.046 \\
\hline Intermediate & 0.183 & 0.051 & 0.153 & 0.044 & 0.157 & 0.044 \\
\hline Near & 0.196 & 0.057 & 0.192 & 0.052 & 0.195 & 0.052 \\
\hline Nearest & 0.246 & 0.061 & 0.428 & 0.119 & 0.216 & 0.060 \\
\hline
\end{tabular}

To evaluate this behavior when system volume varies, two quantifiers were introduced: the envelope spectrum and the variance spectrum RMS values (both of them were calculated from the same spectra set). So, Table 3 shows the quantifier values of three different system configurations in case of compressor operating conditions gradually closer to the surge event.

Table 3 shows that, in all the considered conditions, these quantifiers (env. and $\sigma$ ) seem suited to identify the approach to the surge condition because near to this condition their values rise significantly. Both the envelope and the variance RMS values seem to be more sensitive for system configuration characterized by $2.3 \mathrm{~m}^{3}$ additional volume. This aspect further confirms the existence of specific volume values able to amplify the vibration response. 
Table 4. Main line valve closing: envelope and variance sub-synchronous cross spectra RMS values at different volume values (time intervals from surge events: "Far" means $700 \mathrm{~s}$, "Intermediate" is $200 \mathrm{~s}$, "Near" is $100 \mathrm{~s}$, and "Nearest" is for $1 \mathrm{~s}$ before surge).

\begin{tabular}{|c|c|c|c|c|c|c|}
\hline & \begin{tabular}{|c|} 
RMS \\
env. \\
$4.1 \mathrm{~m}^{3}$ \\
\end{tabular} & $\begin{array}{c}\text { RMS } \\
\sigma \\
4.1 \mathrm{~m}^{3} \\
\end{array}$ & \begin{tabular}{|c} 
RMS \\
env. \\
$2.3 \mathrm{~m}^{3}$ \\
\end{tabular} & $\begin{array}{c}\text { RMS } \\
\sigma \\
2.3 \mathrm{~m}^{3} \\
\end{array}$ & \begin{tabular}{|c|} 
RMS \\
env. \\
$0.3 \mathrm{~m}^{3}$ \\
\end{tabular} & $\begin{array}{c}\text { RMS } \\
\sigma \\
0.3 \mathrm{~m}^{3}\end{array}$ \\
\hline $\mathrm{ar}$ & 0.489 & 0.235 & 0.540 & 0.258 & 0.543 & 0.261 \\
\hline Inter & 0.525 & 0.250 & 609 & 0.293 & 0.545 & 0.262 \\
\hline Near & 0.601 & 0.293 & 0.673 & 0.330 & 0.638 & 0.312 \\
\hline Near & 0.636 & 0.312 & 1.101 & 0.530 & 0.750 & 0.355 \\
\hline
\end{tabular}

Accelerometer and microphone signals frequency content were used synergistically through the calculation of crosspower spectrum. It contains only the common frequency contents of the accelerometer and microphone signal. So, the obtained spectrum provides the information contained in a signal (for example the microphone) filtered by the frequency content of the second signal (axial accelerometer). This approach allows to underline the common frequency components between the two signals. The same quantifiers previously used on accelerometer spectra, were applied on cross-spectra between the microphone and accelerometer signal. Results reported in Table 4, referred to the analysis on cross spectra, show a better predictive performance of quantifiers.

A further analysis was carried out considering the application of chaos theory on acquired signals to evaluate the possibility of early detection of surge incipient condition $[32,34]$. It is assumed that phenomena related to the condition of incipient surge generate a system response with non-linear contributions $[35,36]$. For this reason, it seems coherent to apply chaos quantifiers to diagnose the occurrence of the phenomenon. Initially, phase plane was reconstructed starting from the acquired experimental signals. Two criteria were followed. The first one is more exact and provides a single and double integration on the accelerometer signals that allows reconstructing the attractor in the displacement-speed plane. The second one, through the definition of a proper delay, provides a pseudo phase plane, which also contains information related to the presence of non-linearity in the observed system. The advantage of the second method is the direct use of the raw signal, thus avoiding the integration procedure that may affect the final results.

System non-linearity presence and the related amount may be quantified by evaluating the attractor fractal dimension $[35,37,38]$. In this study the fractal dimension was evaluated through different definitions available in literature [34,35]. Chaos analysis was carried out using only the experimental data of sub-synchronous components: as from the previous analysis they seem to be the most significant in terms of contributions related to the incipient detection surge phenomenon. Figure 20 shows the phase plane evaluated in stable condition of the compressor (700 s from surge event) and in the near surge zone ( $1 \mathrm{~s}$ from the surge event).

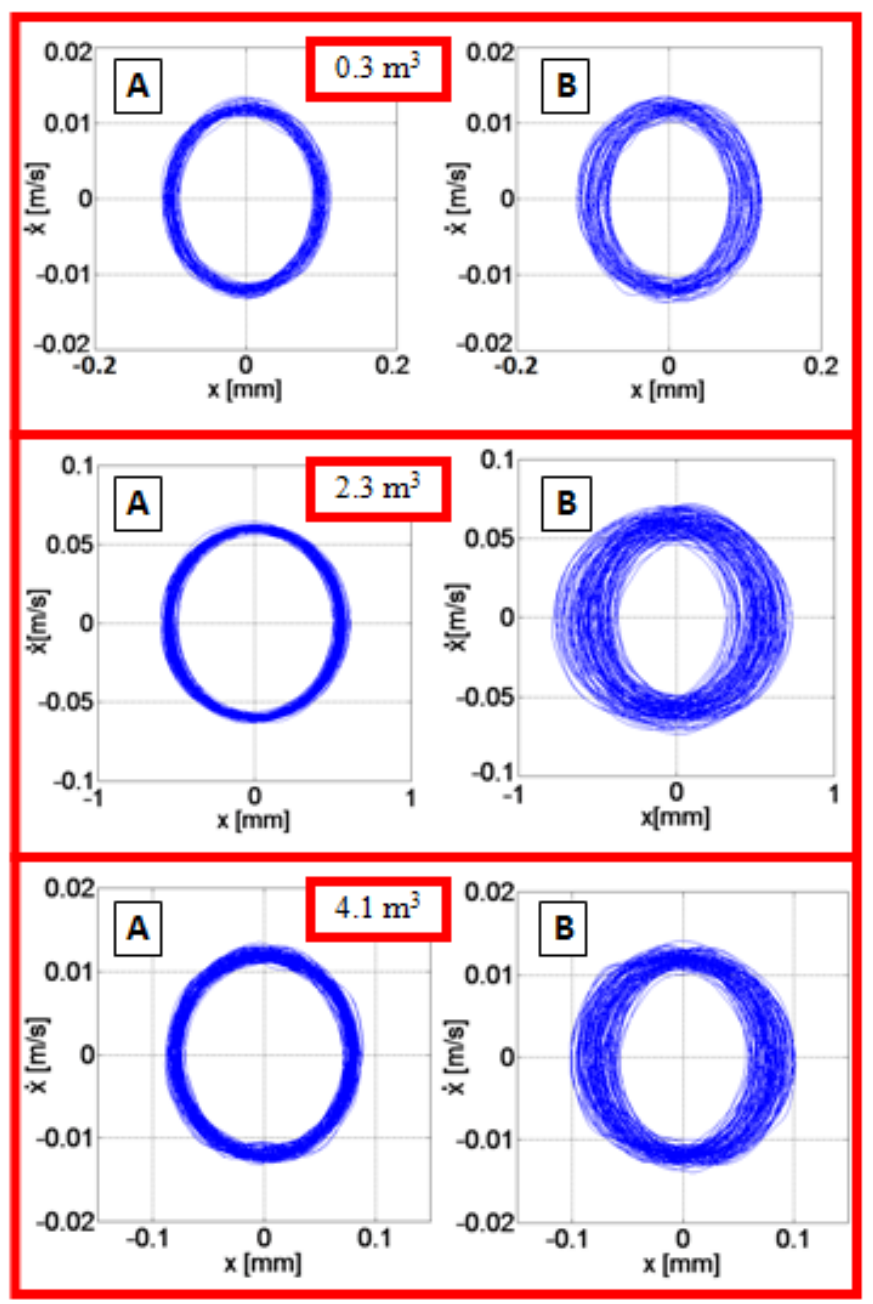

Figure 20. Main line valve closing: phase plane calculated through the axial acceleration signal considering single and double integration in two different instants far (parts A) and near (parts B) to the surge event with the three different volume sizes.

It is clear (from Figure 20) that, for all the volume cases, in the near zone to surge events (parts B) the attractors present a greater complexity probably related to the system cyclical and deterministic nature reduction. This phenomenon is likely due to the occurrence of random vibratory components which leads to non-linearity in the system. It was evaluated the increase of the phase plane complexity from a stable (parts A) to an incipient surge (parts B) condition. While this phenomenon is significant in all volume cases, for the $2.3 \mathrm{~m}^{3}$ size it is possible to show a sort of amplification of surge associated phenomena.

This effect was also quantified by evaluating the information dimension. It is a chaos indicator that quantifies the system chaotic behavior through the calculation of the fractal 
dimension of the attractor, which in this case is the phase plane. This method provides information through a time domain analysis as it considers the phase plane reconstructed using acquired time histories without using FFT algorithms, and so it seems to give additional information with respect the previous methods. Figure 21 shows the trend of this indicator for the different additional volume configurations during the transient operations for several instants, expressed in seconds before reaching the surge events (located at time zero).

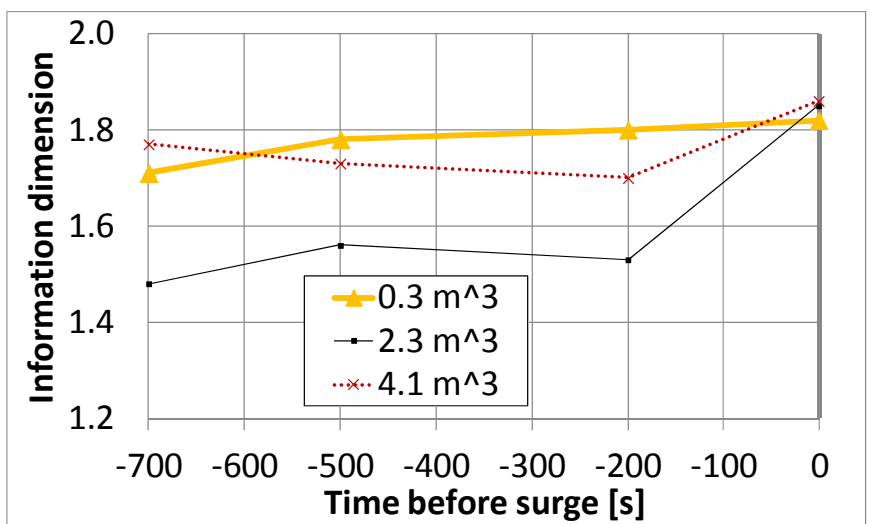

Figure 21. Main line valve closing: information dimension trend varying the distance in seconds from the surge (from the pseudo phase planes).

With this final analysis, it is possible to highlight that this indicator is very sensitive to the detection of the unstable surge condition (rising behavior close to zero). While in the $0.3 \mathrm{~m}^{3}$ the parameter increase is shown by a monotonous trend, also in the other cases the values close to the surge events $(1 \mathrm{~s}$ before instability) are significantly higher than the values obtained in the other instants. Information dimension, which is calculated considering the phase plane through acquired signal time domain analysis, is useful for the development of a diagnostic system together with the previous indicators.

\section{CONCLUSIONS}

This work shows an experimental campaign to analyze the effect of different volume sizes connected with a gas turbine due to its importance in advanced cycles (e.g. fuel cell based hybrid plants, humid cycles, externally fired layouts and innovative systems including high temperature thermal storage devices). The tests were carried out with the experimental facility including a T100 microturbine connected with a modular vessel (to change the volume size) between the recuperator outlet duct and the combustor inlet line. The main results obtained with these tests are summarized in the following points.

- The tests on the bleed valve were necessary to evaluate the pressure time response increase with the volume increase. The different peak time values were: $10.1 \mathrm{~s}$ for $4.1 \mathrm{~m}^{3}, 7.8 \mathrm{~s}$ for $2.3 \mathrm{~m}^{3}$ and $2.3 \mathrm{~s}$ for $0.3 \mathrm{~m}^{3}$.
- The tests related to surge conditions showed the volume effect in terms of oscillation frequency for the recuperator inlet pressure on the cold side (from about $0.4 \mathrm{~Hz}$ with $4.1 \mathrm{~m}^{3}$ additional volume to $1.3 \mathrm{~Hz}$ for the $0.3 \mathrm{~m}^{3}$ case). In this case it was not possible to calculate these frequency values with the Helmholtz equation [37].

- $\quad$ The surge condition tests also showed that the surge zone was the same for all cases without any significant volume size effect. This result is in agreement with the behavior presented for large size turbines [39].

- Diagnostics, acoustic and vibration investigation seem to show an interesting solution to predict the incipient surge condition using suitable quantifier calculated both in the time and in the frequency domain from accelerometer and microphone signals. This analysis is considered essential to develop an advanced control system able to prevent surge conditions on the basis of such precursors.

- $\quad$ Spectrum energy level seems useful as a quantifier for the surge prediction. Higher sensitivity may be obtained by analyzing the energetic level of specific frequency bands (which, in the study of this specific case, was between $40-60 \%$ of rotational frequency) internal to the sub-synchronous spectrum. However, to generalize the quantifier efficacy to different machinery and plant configuration, it seems more convenient to employ the energetic level of the entire sub-synchronous band.

- Promising prediction and diagnostic results were obtained through analyzing and quantifying the stationarity lack of vibrational and acoustic signals through the definition of envelope and variance function. This function was calculated from a number of spectral sets acquired from equal and consecutive time intervals.

- In addition, the work considered the possibility to define an indicator using the chaos theory, which analyzed the experimentally acquired signals exclusively in the time domain. Also in this case, it could be observed that the fractal dimension can be suitable for diagnostic purpose too.

- Comparing the analyzed data from different plant conditions for the purpose of the incipient surge identification, some condition seems to exist in which the surge indicators become more efficient. This may be related to the presence of specific volumes that amplify the surge associated phenomena. In this specific case the configuration with the intermediate additional volume $\left(2.3 \mathrm{~m}^{3}\right)$ presented a higher sensitive quantifier.

In an ongoing activity, a real application of surge detection technique (based on such precursors) and the related prevention 
carried out by the control system will be performed with this test rig.

\section{REFERENCES}

[1] Sheikhbeigi B., Ghofrani, M.B.. Thermodynamic and environmental consideration of advanced gas turbine cycles with reheat and recuperator. International Journal of Environmental Science and Technology, 4 (2007) 253-262.

[2] Fernández P., Miller F., Assessment of the overall efficiency of gas turbine-driven CSP plants using small particle solar receivers. Energy Procedia, 49 (2013) 334343.

[3] Klotz D., Leonide A., Weber A., Ivers-Tiffée E., Electrochemical model for SOFC and SOEC mode predicting performance and efficiency. International Journal of Hydrogen Energy, 39 (2014) 20844-20849.

[4] Montero Carrero M., De Paepe W., Parente A., Contino F., T100 mGT converted into mHAT for domestic applications: Economic analysis based on hourly demand. Applied Energy 164 (2016) 1019-1027.

[5] Jia Z., Sun J., Dobbs H., King J., Feasibility study of solid oxide fuel cell engines integrated with sprinter gas turbines: Modeling, design and control. Journal of Power Sources, 275 (2015) 111-125.

[6] Traverso A., Magistri L., Massardo A.F., Turbomachinery for the air management and energy recovery in fuel cell gas turbine hybrid systems. Energy 35 (2010) 764-777.

[7] Henke M., Monz T., Aigner M., Introduction of a New Numerical Simulation Tool to Analyze Micro Gas Turbine Cycle Dynamics. Journal of Engineering for Gas Turbine and Power, 139 (2017) 042601_1-7.

[8] Wolf J., Barone F., Yan J., Performance analysis of evaporative biomass air turbine cycle with gasification for topping combustion. Journal of Engineering for Gas Turbines and Power, 124 (2002) 757-761.

[9] Qiu K., Yan L., Ni M., Wang C., Xiao G., Luo, Z., Cen, K., Simulation and experimental study of an air tubecavity solar receiver. Energy Conversion and Management, 103 (2015) 847-858.

[10] Luo Z., Wang C., Xiao G., Ni M., Cen K., Simulation and experimental study on honeycomb-ceramic thermal energy storage for solar thermal systems. Applied Thermal Engineering, 73 (2014) 620-626.

[11] Yan J., Chou S.K., Desideri U., Xia X., Innovative and sustainable solutions of clean energy technologies and policies (Part I). Applied Energy, 130 (2014) 447-449.

[12] Kabalyk K., Liskiewicz G., Horodko L., Kryłłowicz W., Stickland M., Use of pressure spectral maps for analysis of influence of the plenum volume on the surge in centrifugal blower. ASME Paper GT2014-26931, ASME Turbo Expo 2014, Dusseldorf, Germany.
[13] Lï̈kiewicz G., Horodko L., Time-frequency analysis of the Surge Onset in the Centrifugal Blower. Open Engineering, 5 (2015) 299-306.

[14] Ferrari M.L., Pascenti M., Magistri L., Massardo A.F., MGT/HTFC hybrid system emulator test rig: Experimental investigation on the anodic recirculation system. Journal of Fuel Cell Science and Technology, 8 (2011) 021012_1-9.

[15] Larosa L., Traverso A., Ferrari M.L., Zaccaria V., Pressurized SOFC hybrid systems: Control system study and experimental verification. Journal of Engineering for Gas Turbines and Power, 137 (2015) 031602_1-8.

[16] Greco A., Sorce A., Littwin R., Costamagna P., Magistri L., Reformer faults in SOFC systems: Experimental and modeling analysis, and simulated fault maps. International Journal of Hydrogen Energy, 39 (2014), 21700-21713.

[17] Baudoin S., Vechiu I., Camblong H., Vinassa J.-M., Barelli L., Sizing and control of a Solid Oxide Fuel Cell/Gas microTurbine hybrid power system using a unique inverter for rural microgrid integration. Applied Energy, 176 (2016) 272-281.

[18] Arnulfi G.L., Giannattasio P., Giusto C., Massardo A.F., Micheli D., Pinamonti P., Multistage Centrifugal Compressor Surge Analysis. Part I: Experimental Investigation, Journal of Turbomachinery. 121 (1999) 305-311.

[19] Arnulfi G.L., Giannattasio P., Giusto C., Massardo A.F., Micheli D., Pinamonti P., Multistage centrifugal compressor surge analysis: Part II-numerical simulation and dynamic control parameters evaluation. Journal of Turbomachinery, 121 (1999) 312-320.

[20] Ferrari M.L., Pascenti M., Magistri L., Massardo A.F., Hybrid system test rig: Start-up and shutdown physical emulation. Journal of Fuel Cell Science and Technology, 7 (2010) 021005_1-7.

[21] McLarty D., Kuniba Y., Brouwer J., Samuelsen S., Experimental and theoretical evidence for control requirements in solid oxide fuel cell gas turbine hybrid systems. Journal of Power Sources, 209 (2012) 195-203.

[22] Pezzini P., Tucker D., Traverso A., Avoiding compressor surge during emergency shutdown hybrid turbine systems. Journal of Engineering for Gas Turbines and Power 2013;135(10): 102602 1-10.

[23] Zaccaria V., Tucker D., Traverso A., A distributed realtime model of degradation in a solid oxide fuel cell, part I: Model characterization. Journal of Power Sources, 311 (2016) 175-181.

[24] Fanyu L., Jun L., Stall Warning Approach With Application to Stall Precursor-Suppressed Casing Treatment. ASME Paper GT2016-58172, ASME Turbo Expo 2016, Seoul, South Korea.

[25] Munari E., Morini M., Pinelli M., Spina P.R., Suman A, Experimental Investigation of Stall and Surge in a 
Multistage Compressor. ASME Paper GT2016-57168, ASME Turbo Expo 2016, Seoul, South Korea.

[26] Ferrari M.L., Pascenti M., Sorce A., Traverso A., Massardo A.F. Real-time tool for management of smart polygeneration grids including thermal energy storage. Applied Energy, 130 (2014) 670-678.

[27] Zhou N., Yang C., Tucker D., Pezzini P., Traverso A., Transfer function development for control of cathode airflow transients in fuel cell gas turbine hybrid systems. International Journal of Hydrogen Energy, 40 (2016) 1967-1979

[28] Hohloch M., Huber A., Aigner M., Experimental Investigation of a SOFC/MGT Hybrid Power Plant Test Rig: Impact and Characterization of a Fuel Cell Emulator. ASME Paper GT2016-57747, ASME Turbo Expo 2016, Seoul, South Korea.

[29] Morini M., Pinelli M., Venturini M., Acoustic and Vibrational Analyses on a Multi-Stage Compressor for Unstable Behavior Precursor Identification. ASME Paper GT2007-27040, ASME Turbo Expo 2016, Montreal, Canada.

[30] Ferrari M.L., Traverso A., Massardo A.F., Smart polygeneration grids: experimental performance curves of different prime movers. Applied Energy, 162 (2016) 662-630.

[31] http://www.lgvipclub.com.ua/content/files/absorption c hillers_8p.pdf [last access 07/10/2016].
[32] Greitzer E.M., Surge and Rotating Stall in Axial Flow Compressors. Part I: Theoretical Compression System Model. Journal of Engineering for Power, 98 (1976) 190-198.

[33] Hagino N., Uda K., Kashiwabara Y., Prediction and Active Control of Surge Inception of a Centrifugal Compressor. Proceedings of the International Gas Turbine Congress, 2003.

[34] Moon C., Chaotic vibrations, John Whiley \& Sons, Inc., 1987.

[35] Adams M.L., Abu-Mahfouz I.A., Exploratory research on chaos concepts as diagnostic tools for assessing rotating machinery vibration signatures. In Proceedings of IFTOMM 3th International Conference on Rotor Dynamics, Chicago, IL, 1994.

[36] Abu-Mahfouz I.A., Routes to chaos in rotor dynamics, PhD Thesis - Case Western Reserve University - Dept. of Mech. and Aerospace Eng. - Supervisor prof. M.L. Adams, 1993.

[37] Hillborn R., Chaos and non linear dynamics. Oxford University Press, Oxford, 1994.

[38] Ehrich F.F., Some observations of chaotic vibration phenomena in high-speed rotordynamics. Journal of vibration and acoustics, 113 (1991) 50-57.

[39] Day I.J., Greitzer E.M, Cumpsty N.A., Prediction of Compressor Performance in Rotating Stall. Journal of Engineering for Power, 100 (1978) 1-12. 